\title{
El obrador de Miguel de Santiago en sus primeros años: 1656-1675
}

\author{
Ángel Justo EstebaranZ \\ Universidad de Sevilla \\ ajestebaranz@us.es
}

Recepción: 15 de mayo de 2009 / Revisión: 17 de noviembre de 2009

Aceptación: 2 de diciembre de 2009 / Publicación: diciembre de 2010

\begin{abstract}
RESUMEN
Este trabajo está dedicado al estudio del obrador del pintor quiteño Miguel de Santiago durante las dos primeras décadas de su existencia, abordando la vida de los colaboradores, su relación con el maestro y su obra. En él se estudian las figuras de Simón de Valenzuela, Bernabé Lobato, fray Alonso Vera de la Cruz y Carreño, hasta ahora prácticamente desconocidas. Asimismo, se analiza la intervención de estos pintores en las primeras series de pinturas de Miguel de Santiago, así como las influencias del maestro en sus discípulos y su habilidad artística. La delimitación temporal elegida viene dada por ser entre ambas fechas, 1656 y 1675, que los primeros colaboradores de Miguel de Santiago están documentados.
\end{abstract}

Palabras clave: Miguel de Santiago, obrador, pintura quiteña virreinal, Quito, siglo XVII.

\section{The Atelier of Miguel de Santiago in its Early Years: 1656-1675}

\begin{abstract}
This paper is dedicated to the study of the atelier of the painter from Quito, Miguel de Santiago, during the first two decades of its existence. The paper discusses the life of his collaborators, their relationship with Santiago and his work. In this paper the figures of Simón de Valenzuela, Bernabé Lobato, and brother Alonso Vera de la Cruz y Carreño, practically unknown until now, are studied. Likewise, these painters' intervention in the first series of paintings by Miguel de Santiago is analyzed, as well as the master's influence on his pupils and their artistic skills. The elected timeframe in the title, between 1656 and 1675, responds to the dates for which there is documentation on the first collaborators of Miguel de Santiago.
\end{abstract}

Keywords: Colonial Art, Miguel de Santiago, Quito, Atelier, 17th Century.

SUMARIO: 1. Introducción. 2. Simón de Valenzuela. 3. Bernabé Lobato. 4. Fray Alonso Vera de la Cruz. 5. Bernabé Carreño. 6. Balance del magisterio. 7. Conclusiones. 8. Referencias bibliográficas.

\section{INTRODUCCIÓN}

Miguel de Santiago es el principal pintor quiteño del siglo XVII. Nacido hacia 1633, desde mitad de los años 50 estuvo al frente de un obrador en el que se formaron varias generaciones de pintores que colaboraron con el maestro en las series pictóricas más importantes de su época dentro de la Real Audiencia de Quito. Este taller se mantendría activo al menos hasta el fallecimiento de Santiago en 1706, aunque es posible que a su muerte continuase durante un tiempo al mando de su hija Isabel de Santiago. Si es cierto que la figura del maestro suscitó el interés de los historiadores de manera más prolija, los colaboradores del mismo sólo eran conocidos muy par- 
cialmente, en base más a suposiciones que a documentos que los relacionasen con Miguel de Santiago. De hecho, este desconocimiento se hace extensible al resto de obradores quiteños del siglo XVII, no sucediendo lo mismo en la centuria siguiente, cuando son conocidos, aunque de forma parcial, varios aspectos e integrantes de los obradores de José Cortés de Alcocer, Bernardo Rodríguez o Manuel Samaniego. Por otra parte, la falta de firmas en las pinturas, tan usual en el Quito de la época, no facilitaba la tarea de discernir qué obras pertenecían al círculo de Miguel de Santiago ${ }^{1}$. En este sentido, más suerte han tenido los historiadores del arte mexicano del siglo XVII, que se han encontrado con una mayor cantidad de firmas que han servido como punto de apoyo sobre el que asentar características de estilo y filiaciones artísticas $^{2}$. En nuestra monografía sobre Miguel de Santiago en San Agustín de Quito ${ }^{3}$ y en nuestra Tesis Doctoral, Miguel de Santiago y la pintura quiteña de su época (1630-1720) ${ }^{4}$, tuvimos ocasión de acercarnos a las figuras de los colaboradores de Miguel de Santiago. Este trabajo está dedicado al estudio del obrador de Santiago durante las dos primeras décadas de su existencia, abordando la vida de los colaboradores, su relación con Santiago y su obra. La delimitación temporal elegida en el título del artículo viene dada por ser entre ambas fechas que los primeros colaboradores de Miguel de Santiago están documentados.

Miguel de Santiago alcanzó a edad temprana el grado de maestro pintor. Desde ese momento se puso al frente de un obrador en el que trabajaron varios oficiales. A pesar de ser de raza india, Santiago consiguió alcanzar el grado de maestro y pudo abrir su propio obrador ${ }^{5}$. Varios autores han debatido acerca de las fechas en que el obrador de Miguel de Santiago comenzó a funcionar. Costales Samaniego cree que en 1669 Miguel de Santiago era todavía un oficial pintor, porque de esta manera se hacía referencia a él en un documento, y que podría trabajar en el obrador que el maestro pintor Diego Orozco poseía en la calle de la Ronda ${ }^{6}$. Así, en estos años Santiago aún no tendría obrador propio. El documento a que se refiere Costales

${ }^{1}$ De hecho, tan sólo aparecía el nombre de Carreño en un cuadro, y el de Fray Alonso Vera de la Cruz en otro.

2 Un estudio capital es el ya clásico de Toussaint 1965. Sobre las firmas de los pintores novohispanos, un interesante estudio de Bargellini demuestra su valía como fuente de información sobre el pensamiento de los pintores acerca de la creación y recepción de sus obras. Asimismo, señala que la obligatoriedad de firmar, según las segundas ordenanzas de pintores pregonadas en 1687, estaba relacionada con cuestiones de compra y venta, "de los derechos exclusivos de los maestros pintores para vender y de las atribuciones legales de los veedores, quienes eran ellos mismos maestros examinados, para defender estos derechos". Véase BARGELLINI, 2006, p. 205.

3 Justo Estebaranz, 2008a.

4 Justo Estebaranz, 2008b.

${ }^{5}$ Gutiérrez señalaba al respecto que, aunque al comienzo de la conquista, el privilegio de maestro estaba reservado a españoles que fuesen cristianos viejos, en poco tiempo estas medidas tuvieron que abandonarse en América. Véase GuTIÉRREZ, 1995, pp. 32-33. En cuanto a la raza de Miguel de Santiago, aunque no se especifica en la documentación la de su madre, que se ha tenido por india, sí encontramos la relativa a su padre, Lucas Vizuete, que era un pintor indio. Véase: Venta de un pedazo de tierra, Lucas Bizuete y Francisca Mendiola a Bartolomé Lemo, indio frutero. Quito, 16-II-1657. Archivo Nacional de Historia del Ecuador (en adelante ANH), sección Protocolos Notariales, $4^{a}$ notaría, vol. 15, ff. 79r-81v.

6 Costales Samaniego, 2007, p. 225. 
Samaniego, que además no cita correctamente, es una "Declaración de Miguel de Santiago, oficial pintor, a favor de Ana Rozero", realizada en 1669, por unas tierras que le vendió Bernabé Lobato7. Pero este documento no es determinante en relación a este punto, pues ya en el de venta de dichas tierras, de 1662, se le nombra como maestro pintor, figurando Bernabé Lobato como oficial pintor ${ }^{8}$. Este documento demuestra que Miguel de Santiago ya era maestro en 1662, y que Bernabé Lobato tenía relación con él, muy probablemente de discipulado, pues aparece como oficial pintor. Además, en la serie de pinturas sobre la vida de San Agustín que Santiago había terminado en 1656, en la cartela inferior del cuadro de la Dedicatoria, se le nombra a él y no a sus ayudantes como autor de algunas de las pinturas ${ }^{9}$. Dicho encargo se hizo a su obrador, y no al de Diego de Orozco, a quien hubiera debido de realizarse si, como cree Costales Samaniego, Miguel de Santiago aún no poseyera el suyo propio. Creemos que es posible que se produjese un error del escribano al redactar el documento que en 1669 alude a Miguel de Santiago como oficial.

El obrador que Miguel de Santiago poseía en Quito funcionó al menos desde 1654-56 hasta el final de su vida ${ }^{10}$. En la época en que muere Santiago ya no vivía Antonio Egas, con lo que el obrador debía de estar integrado por Isabel de Santiago y otros oficiales desconocidos. El elevado número de pinturas a medio terminar que el pintor cita en su testamento muestra que la demanda de obra de Miguel de Santiago era muy grande en su etapa de madurez, pues era un pintor muy apreciado, como prueba la documentación de esos años, y debía contar con oficiales capacitados para finalizar sus pinturas ${ }^{11}$.

No se sabe con seguridad quién heredó el taller de Santiago, pues la documentación es imprecisa al respecto. A diferencia de otros artistas contemporáneos, Miguel de Santiago no deja en sus cláusulas testamentarias ni útiles de la pintura, ni cuadros, ni encargos a ningún discípulo ${ }^{12}$. Tan sólo nombra a Antonio Egas. Rodríguez Castelo creyó herederos del obrador a su hija Isabel, su yerno Antonio Egas Venegas de Córdoba, Bernardo Lobato y Simón de Valenzuela ${ }^{13}$. Pero esta afirmación no puede ser cierta, al menos en su totalidad, pues Antonio Egas ya había muerto cuando testó Miguel de Santiago ${ }^{14}$. Como su hija Isabel y su nieto Agustín Ruiz fueron nombrados herederos universales, es de suponer que fuera ella quien se hiciera cargo

7 Declaración de Miguel de Santiago, oficial pintor, a favor de Ana Rozero. Quito, 2-III-1669. ANH, sección Protocolos Notariales, $1^{\text {a }}$ notaría, vol. 226, f. 85.

8 Traspaso de Juana Flores, india, a favor de Bernabé Lobato, de un pedazo de tierra. Quito, 3-I1662. ANH, sección Protocolos Notariales, $1^{\mathrm{a}}$ notaría, vol. 206, f. 608 r.

${ }^{9}$ La inscripción es la siguiente: Este lienço con 12 o mas Pinto Miguel de Santiago en todo este año de (1)656 en que se acabó esta historia. Véase Justo EsteBARANZ 2008a, p. 103.

10 Es muestra de su actividad hasta el final de sus días, en 1706, la cuarentena de telas y lienzos que Miguel de Santiago dejaba en esbozo cuando testó, cinco días antes de su muerte.

11 Testamento de Miguel de Santiago. Quito, 31-XII-1705. ANH, sección Protocolos Notariales, $4^{\mathrm{a}}$ notaría, vol. 56 , f. $15 \mathrm{r}$.

12 Ibidem, ff. 7r-16v. De hecho, aunque cita bastantes pinturas, no las deja en herencia a ningún colaborador, sino a sus herederos universales.

13 Rodríguez CAStelo, 1993. http://www.edufuturo.com/educacion.php?c=1750 (Consultada el $15 / 04 / 2009)$.

14 Para más información sobre Antonio Egas, véase Justo EsteBARANZ, 2009, pp. 75-97. 
del obrador, y en quien recayesen los encargos sin terminar. Esta suposición vendría reforzada por el hecho de que Agustín era menor de edad, y también por la historiografía clásica, que se refiere a Isabel como pintora. Lo extraño es que Isabel no mencione en su primer testamento ni el taller, ni los cuadros ${ }^{15}$; aunque sí lo hace en el segundo, en el que admite haberse hecho cargo de algunas pinturas ${ }^{16}$. Así, lo más probable es que Isabel dirigiese el obrador hasta 1714, año de su muerte. Otra posibilidad es que se hicieran cargo Bernabé Lobato o Simón de Valenzuela, a los que se les pierde la pista documental antes, con lo que no sabemos si para entonces aún seguían vivos o ya habían fallecido. Otro posible encargado del taller pudo ser Nicolás Javier de Goríbar, o quizás algún oficial desconocido, aunque nos inclinamos a pensar que Isabel heredó el obrador.

En el taller de Miguel de Santiago se integraron pintores de muy distinta condición y raza, desde capitanes españoles -Antonio Egas-, hasta mulatos -Simón de Valenzuela-, e indios como el propio maestro. Incluso se podría citar a fray Alonso Vera de la Cruz, el fraile agustino que colaboró en algunas de las pinturas sobre la vida de San Agustín. El escritor ilustrado ecuatoriano Eugenio de Santa Cruz y Espejo nombra a un famoso pintor, Gregorito, que consideraba muy habilidoso, pero vago como Miguel de Santiago, de quien Vargas creía que era discípulo ${ }^{17}$. De este pintor y de su relación con Santiago no hemos encontrado constancia documental alguna.

Miguel de Santiago influyó en un círculo que se circunscribe a su obrador y quizás a las ciudades a las que mandó obras, como serían Bogotá y Santiago de Chile, si es que la serie que llegó allí salió de su taller, algo que no creemos, pues en el segundo caso la escasa calidad pictórica de los lienzos dista mucho de los logros de Santiago y su obrador. En Quito se observan determinadas pinturas que siguen la estela de Miguel de Santiago en la manera de componer, como algunas Inmaculadas Eucarísticas, y otras que se fijan en determinados rostros.

Kennedy señaló como alumnos destacados de Miguel de Santiago a Nicolás Javier de Goríbar, Isabel de Santiago, Antonio Egas, Bernabé Lobato, Simón de Valenzuela y el pintor Gregorito, quienes irían consolidando una imagen barroca desde el sector criollo urbano ${ }^{18}$. A éstos añadían Guido y el Marqués de Lozoya a Bernardo Rodríguez, que vivió en la segunda mitad del siglo XVIII ${ }^{19}$. Navarro afirma que Morales y Vela eran compañeros de taller y, probablemente, discípulos de Goríbar, y que ambos ayudaron a aquél y a Miguel de Santiago en la realización de

15 Poder para testar de Isabel de Cisneros (de Santiago) al licenciado Gregorio Lepe. Quito, 17-II1714. ANH, sección Protocolos Notariales, $3^{\mathrm{a}}$ notaría, vol. 35, ff. 443r-445r.

16 Testamento de doña Isabel de Cisneros (de Santiago). Quito, 17-V-1714. ANH, sección Protocolos Notariales, $4^{\mathrm{a}}$ notaría, vol. 65 , ff. $127 \mathrm{r}-129 \mathrm{v}$.

17 SANTA CruZ y Espejo, 1923, pp. 198-199 y Vargas, 1944, p. 121.

18 KenNEDY, 2002, p. 50.

19 Contreras, 1945, p. 303 y Guido, 1944, p. 282, quien nombra también a Vela y Morales. Bernardo Rodríguez no pudo ser discípulo de Miguel de Santiago por una simple cuestión de fechas, pues nació después de que el primero hubiese muerto. Pero es que además su estilo poco o nada debe a la producción de Santiago, y sí a los grabados rococó que le sirvieron de modelo, relacionándose asimismo con otros pintores contemporáneos como los Albán, Cortés y sobre todo Samaniego, con quien trabajó conjuntamente en algunas obras. 
las pinturas de la vida de San Agustín ${ }^{20}$. En los mismos términos se expresó Tobar Donoso, quien les puso nombre: Andrés Morales y el morlaco Vela ${ }^{21}$. Destruge añade a estos dos nombres el de Oviedo, otro supuesto discípulo 22 . No obstante, de ellos no se ha encontrado ninguna documentación en los archivos quiteños, y Goríbar aún no había nacido cuando se pintaron los cuadros de San Agustín, con lo que no pudo colaborar en esas pinturas. Además, el padre Velasco proporciona a finales del siglo XVIII información decisiva para desechar el discipulado de Morales, Vela y Oviedo. Respecto a Andrés Morales, asegura que vivió en los tiempos medios, después de Miguel de Santiago. De Vela, a quien llama Maestro, y Oviedo, dice que los conoció $^{23}$. Los dos primeros eran de Cuenca, mientras que el Maestro Oviedo era nativo de Ibarra ${ }^{24}$. Aún hay otro dato interesante, pues el jesuita diferencia entre el Maestro Vela y el Morlaco, también cuencano, a quien Tobar Donoso confundía con Vela. Estos pintores estaban en competencia y tenían sus partidarios protectores, según asegura Velasco.

En el obrador de Miguel de Santiago se formaron varias generaciones de artistas, de las que al menos conocemos dos. A la primera pertenecerían Lobato, Valenzuela, Carreño y fray Alonso Vera de la Cruz, y a la segunda su hija Isabel, Antonio Egas y Nicolás Javier de Goríbar. La historiografía del arte ecuatoriano ha tendido a relacionar la formación de estos discípulos con dos series: la de San Agustín y la de Guápulo, pretendiendo que su aprendizaje se realizaría dentro de ambos conventos ${ }^{25}$. Si no es descabellado pensar que, efectivamente, cada generación colaboraría en una de estas series, sí resulta extraño que el pintor trasladase su obrador al mismo cenobio, pues tenía su residencia-taller muy cerca de San Agustín (lo que le permitía trabajar en ella sin desplazarse al convento), mientras que a Guápulo llevaría las pinturas que habría realizado en Quito, colocándose posteriormente en la sacristía.

Desde sus comienzos, Santiago se ayudó de varios oficiales en los grandes encargos de series, confiándoles la realización de cuadros enteros y haciéndose cargo él mismo de los que consideraba más importantes. Así, ya indicamos en nuestro libro Miguel de Santiago en San Agustín de Quito cómo el maestro se reservó las pinturas de mayor importancia temática y las que habían sufragado personalidades de la ciudad $^{26}$. Según Vargas y Kingman, Santiago acostumbraba a dar las últimas pinceladas a los cuadros de sus discípulos ${ }^{27}$. Ello se comprueba en cuadros de la serie de San Agustín realizados por sus discípulos, con detalles de una calidad superior al resto de la pintura. Asimismo, se observa cómo en otras pinturas, como varias de Guápulo, el

20 NAVARRO, 1985, p. 174.

21 Tobar Donoso, 1953, p. 367. "Morlaco" es un calificativo con que se llamaba en Quito a los cuencanos. Quizás este pintor proviniera de la ciudad de Cuenca.

22 Destruge, 1903, p. 184.

23 Velasco, 1981, p. 321.

24 Este Maestro Oviedo firma un cuadro conservado en el Museo Nacional del Banco Central del Ecuador: la Virgen al pie de la Cruz o Soledad de María. Dicha pintura está fechada el 20 de febrero de 1754, en la ciudad de Ibarra, por "Obiedo".

25 En este sentido, Vargas opinó que Goríbar fue discípulo de Miguel de Santiago en Guápulo. VARGAS, 1960, p. 189.

26 Justo Estebaranz, 2008a, pp. 71-72.

27 VARGAS, 1944, pp. 123-124 y Kingman, 1951, p. 48. 
maestro pintó una parte del lienzo, dejando las zonas menos significativas a otra mano. La intervención del taller se aprecia tanto en los cuadros de San Agustín como en la Doctrina cristiana, la portería de San Francisco, los cuadros de Bogotá y los de Guápulo.

Por otra parte, Miguel de Santiago realizó varias pinturas en solitario, mientras que en otras intervino algún ayudante. La colaboración del obrador en sus series de pinturas dio lugar a composiciones de diferente calidad, siendo algunas de buena factura, y revelando otras una mano menos habilidosa que la del maestro. Aunque la producción del obrador de Miguel de Santiago hubo de ser apreciada en su época, la documentación revela que eran las obras realizadas exclusivamente por el maestro las más codiciadas entre la clientela quiteña. Así, Gerónimo de Quesada se preciaba en 1705 de tener cuatro pinturas de la mano de Miguel de Santiago ${ }^{28}$. De la misma manera, cuando don Gabriel de Zuleta encarga a Miguel de Santiago una pintura por 45 pesos, que además le había adelantado, y éste se los devuelve por cláusula testamentaria aunque su obrador funcionaba a pleno rendimiento, es porque la pintura era un encargo directo al maestro, al que no podría sustituir ningún oficial ${ }^{29}$. Ambos ejemplos prueban la diferencia de estimación entre las pinturas de Miguel de Santiago y las de su obrador.

De las dos generaciones de discípulos citadas antes, es la primera la que ahora nos interesa. Aunque de ella se conocían algunos nombres de colaboradores, era una generación que había permanecido oscura para el historiador del arte ecuatoriano, huérfana de datos documentales y carente de un estudio de su producción. Ahora aportamos datos que esclarecen el panorama del obrador de Miguel de Santiago en sus primeros años de actividad.

Siempre ha habido dos discípulos considerados desde el primer momento como los más fieles a Miguel de Santiago: Bernabé Lobato y Simón de Valenzuela ${ }^{30}$. Herrera aseguraba que ambos pintores eran amigos, socios y compañeros del taller de Santiago ${ }^{31}$. Pero la documentación que a continuación se analiza muestra otras relaciones, no precisamente de socios, sino de pertenencia al taller, pues ambos eran oficiales y Miguel de Santiago el maestro. Lobato y Valenzuela colaboraron con el maestro quiteño ya desde su primera obra, la serie de San Agustín, y seguirían con él durante años. De hecho, salvo en un documento relativo a Bernabé Lobato, del que luego nos ocuparemos, y que puede tener una errata, no se ha encontrado documentación que los acreditase como maestros pintores, figurando en cambio siempre como oficiales durante los años en que están documentados.

28 Testamento de Gerónimo de Quesada. Quito, 17-XI-1705. ANH, sección Protocolos Notariales, $4^{a}$ notaría, vol. 55, f. $367 \mathrm{v}$.

29 Testamento de Miguel de Santiago. Quito, 31-XII-1705. ANH, sección Protocolos Notariales, $4^{\mathrm{a}}$ notaría, vol. 56, f. 16 r.

30 DiCCIONARIO, 1972, p. 575.

31 Citado por NAVARRO, 1991, p. 83. 


\section{SIMÓN DE VALENZUELA}

La documentación notarial presenta a Simón de Valenzuela como un pintor mulato ${ }^{32}$. Por un recibo que otorgan en marzo de 1663 su abuela, su madre y su padre al alférez Alonso Gómez de la Pulla conocemos a su familia33. En este documento se especifica que Simón de Valenzuela era hijo de María de Valenzuela, "morena", y de don Antonio de Monroy, "color pardo", de lo que se desprende que Simón de Valenzuela realmente era zambo y no mulato. De hecho, su madre era negra y su padre mulato, pues el "color pardo" calificaba a esta condición. Pero no es extraño que en la documentación de la época se llamase "mulato" a quien en realidad era zambo. La abuela de Simón, Catalina de Valenzuela, negra, había sido esclava del licenciado Pedro de Valenzuela Tafur, cura beneficiado de la Parroquia de Santa Bárbara. Éste había mandado vender una estancia de diez caballerías de tierra junto al camino que iba al llano de Zambiza, para que se repartiese el dinero entre Catalina, María y sus hijos ${ }^{34}$. Los hermanos de Simón citados en dicho documento son Gregorio, Jerónimo, Margarita, Tomás y Marucha ${ }^{35}$. Su madre y su abuela tomaron su apellido del sacerdote a quien servían, conservándolo también sus descendientes.

Los padres de Simón recibieron 110 pesos de la parte que les tocaba de la venta de las tierras de Pedro de Valenzuela Tafur-que ascendió a 1200 pesos-, pues se iban a la ciudad de los Reyes. Por tanto, Simón se debió quedar en Quito una vez que sus padres abandonaron la ciudad.

No se sabe cuándo manumitió Pedro de Valenzuela Tafur a su abuela. Como en América era usual que los esclavos de nacimiento siguieran la condición de su madre, fuera cual fuere el estado del padre, es de suponer que María de Valenzuela, madre de Simón, también habría sido esclava del cura de Santa Bárbara ${ }^{36}$. Si Simón nació antes de la muerte del religioso podría haber sido también esclavo del mismo, manumitiéndosele a la muerte de aquél.

Por la partida de bautismo de una hija suya sabemos que Simón de Valenzuela era vecino de la collación de Santa Bárbara, como Miguel de Santiago, y que tenía su casa también en el Alto de Buenos Aires. Esta niña es Isabel, hija natural de Luisa de Atensia (quizás Atienza) y de Simón de Valenzuela, que fue bautizada en Santa Bárbara el 19 de febrero de 1661 por el doctor Aguinaga ${ }^{37}$. Suponemos que la pareja, aunque no hubiera contraído matrimonio, estaría bien avenida, pues en las partidas de bautismo del Quito de la época era usual que no apareciese el nombre del

32 Véase Segundo tratado del convento de La Merced de Quito con María Rodríguez sobre la venta de un pedazo de tierra en Santa Bárbara. Quito, 20-XII-1669. ANH, sección Protocolos Notariales, $1^{\text {a }}$ notaría, vol. 221 , f. 446 r.

33 El documento donde se encuentra esta información es una Carta de pago de Catalina de Valenzuela, negra, y su hija al alférez Alonso Gómez de la Pulla. Quito, 29-III-1663. ANH, sección Protocolos Notariales, $5^{\text {a }}$ notaría, vol. 52, f. 97.

34 Ibidem, f. 97 r.

35 Ibídem.

36 Sobre la condición de los esclavos domésticos en la época colonial, véase CoRTÉs ALONSO, 1967.

37 Libro de Bautismos de la Parroquia de Santa Bárbara. Tomo I. Marzo 1645 - Junio 1694, f. 38r. Archivo Arzobispal de Quito (en adelante AAQ). 
padre si el hijo era natural. Por otra parte, el hecho de que la madrina fuese doña Juana de Valenzuela, probablemente pariente de Simón, apoya esta suposición, pues de lo contrario la mujer hubiera buscado a alguien de su familia o de la misma collación.

Simón de Valenzuela figura como testigo en el testamento del pintor Salvador Marín, en $16499^{38}$. Ello quiere decir que en ese año ya sería mayor de edad, con lo que su nacimiento podría situarse, como muy tarde, hacia 1628. Lo extraño es que firma como Simón de los Reyes, aunque en el documento aparece citado como Simón de Valenzuela. Además de él, firmó como testigo Diego Suárez, otro pintor residente en Quito ${ }^{39}$. Este documento es interesante porque demuestra que Simón de Valenzuela era mayor que Miguel de Santiago, que en 1649 ya se relacionaba con otros pintores quiteños - quizás hubiese sido discípulo de Salvador Marín o de Diego Suárez-, y que sería después cuando pasase a formar parte del obrador de Miguel de Santiago.

El 24 de marzo de 1665, el maestro pintor Salvador Marín pretendía comprar un pedazo de tierra yerma y sin construir que pertenecía al convento de La Merced, junto a la casa de Simón de Valenzuela, pintor, por el que pagaría 80 pesos a censo ${ }^{40}$. Parece que Salvador Marín no llegó a comprarlas, pues cuatro años después aparece un tratado del convento mercedario con María Rodríguez, india, quien estaba dispuesta a pagar 100 pesos por esta parcela ${ }^{41}$. De todas maneras, el anterior documento es interesante por volver a poner en relación a Marín y a Valenzuela dieciséis años después de la primera constancia documental de tal relación. Además, es demostrativo de que Simón de Valenzuela estaba vivo en marzo de 1665. A este dato hay que unir la mención a Valenzuela sólo como "pintor" y no como maestro, a diferencia de lo que ocurriría con Miguel de Santiago e incluso con Bernabé Lobato.

El 10 de abril de 1676 los padres maestros fray Fernando de Carvajal y fray Diego Muñoz de Sandoval, mercedarios, acuerdan hacer entrega de 400 pesos a Cristóbal Maldonado, indio, por haber servido al padre fray Joseph Maldonado. Con ese dinero el indio compraría las casas que fueron de Simón de Valençuela pintor, en el barrio de Santa Bárbara ${ }^{42}$. No sabemos si es que el pintor había vendido esas casas, o que por esas fechas ya había muerto. Probablemente su fallecimiento se produjese antes, pues aquí es donde vivía el pintor.

38 Testamento de Salvador Marín. Quito, 14-I-1649. ANH, sección Protocolos Notariales, 6 a notaría, vol. 55, s.f.

39 Este Diego Suárez, pintor, figura como testigo en el enlace matrimonial entre los indios Inés de Zalamea y Francisco Barahona. Dicha unión se celebró en la parroquia de Santa Bárbara el 12 de octubre de 1650. Libro de matrimonios de indios de la Parroquia de Santa Bárbara, 1644-1795, f. 9 (según la numeración antigua, f.8). AAQ. Aunque no se puede afirmar, quizás Diego Suárez fuese indio, por aparecer como testigo en el enlace entre dos indios, y quizás viviese en la misma collación de Santa Bárbara.

40 Tratado entre el convento de La Merced de Quito y Salvador Marín sobre la venta de unas tierras. Quito, 24-III-1665. ANH, sección Protocolos Notariales, $1^{a}$ notaría, vol. 211, ff. 309v-311r.

41 Primer tratado del convento de La Merced de Quito a favor de María Rodríguez, india. Quito, 18-XII-1669. ANH, sección Protocolos Notariales, $1^{\text {a }}$ notaría, vol. 221, f. 444r.

42 Aprobación de entrega de 400 pesos por el convento de La Merced de Quito a favor de Cristóbal Maldonado, indio. Quito, 10-IV-1676. ANH, sección Protocolos Notariales, $1^{\mathrm{a}}$ notaría, vol. 244, f. 219. 
No fue Simón de Valenzuela el único pintor de piel negra que trabajó en Quito. En otro estudio hemos localizado más pintores negros ${ }^{43}$. El acceso de éstos al oficio de pintor no debió de estar prohibido en Quito, como sí lo estaba en Perú, donde se prohibía a los maestros tomar "mulatos, negros y zambos" como aprendices ${ }^{44}$. De esta manera, en la capital de la Real Audiencia hubo hasta esclavos o hijos de esclavos que pasaron a desempeñar el oficio de la pintura ${ }^{45}$.

\section{BERNABÉ LOBATO}

Aunque los historiadores ecuatorianos Navarro y Alarcón Costta se refieren a este artista como Bernardo Lobato, en la documentación quiteña siempre firmó como Bernabé $^{46}$. Este oficial aparece relacionado documentalmente con Miguel de Santiago en varias ocasiones, y siempre figuró en la historiografía del arte quiteño como compañero de Simón de Valenzuela en el obrador del maestro.

Bernabé Lobato y Simón de Valenzuela, oficiales pintores, figuran como testigos de María de Illanes, firmando a ruego de ella, en un poder que la susodicha otorgaba a Miguel de Santiago, "maestro de pintura que de presente va al asiento de Latacunga", para que presentase una carta de justicia requisitoria en su nombre 47 . Este documento muestra a los dos pintores relacionados entre sí y con el maestro, apareciendo como oficiales que lo acompañan en sus asuntos judiciales. Gracias a las firmas de Lobato en el documento citado y en otro más, sabemos que el oficial firmaba como Bernabé de Lobato, quizás para equipararse a Miguel de Santiago y Simón de Valenzuela. Con ello, quizás pretendiese este artista parecer de más alta alcurnia o consideración. De hecho, de la cincuentena de pintores que encontramos en Quito en los años en que vivió Miguel de Santiago, más de diez llevaban la preposición "de" delante del apellido, y la mayoría eran indios, habiendo también españoles, mestizos y un mulato o zambo.

Aunque en 1662 Lobato figura en los documentos como oficial pintor, en una venta de casas en 1661 es señalado como maestro pintor ${ }^{48}$. No sabemos si es una confusión, como también sucedió en otra ocasión con Miguel de Santiago, o si es que en ese año ya tenía el grado de maestro, siendo en 1662 cuando se produce el error en el documento (que analizamos más adelante). Lo cierto es que Bernabé Lobato, así nombrado, vende al tratante Bernardo Pavón una sala en los altos de Santa Bárbara por 100 pesos $^{49}$. La venta incluía la sala cubierta de teja y la mitad del patio

43 Justo Estebaranz, 2008b, p. 93.

44 AlCALÁ, 1998, p. 88.

45 Parece que fue notable la presencia de los negros de Quito en la artesanía, fuera ésta cual fuese. Véase TARDIEU, 2006, p. 199.

46 NaVARro, 1985, p. 172 y Alarcón CostTA, 2000, p. 1072.

47 Poder de María de Illanes a Miguel de Santiago, maestro pintor, para presentar una carta de justicia requisitoria en su nombre. Quito, 6-I-1662. ANH, sección Protocolos Notariales, $1^{\mathrm{a}}$ notaría, vol. 208, f. 3r.

48 Venta de una sala cubierta de teja, de Bernabé Lobato, maestro pintor, a Bernardo Pavón. Quito, 14-XII-1661. ANH, sección Protocolos Notariales, $5^{a}$ notaría, vol. 50, f. 331.

49 Ibidem. 
que le tocaba por herencia materna. Según ese documento, Bernabé Lobato era hijo de Leonor Vizuete, ya fallecida. Esta Leonor Vizuete era la hija legítima del pintor Lucas Vizuete, padre de Miguel de Santiago, de tal manera que el nieto legítimo de Lucas siguió el oficio de su abuelo, continuando una dinastía de pintores. Además, Bernabé Lobato era medio sobrino de Miguel de Santiago, así como vecino suyo, pues residía en el Alto de Santa Bárbara o Alto de Buenos Aires de ese barrio, donde asimismo vivía su maestro. Las casas que vendía Lobato en esta ocasión lindaban con las de su abuela Francisca de Mendiola. Aunque no sabemos con quién se casó Leonor Vizuete, sí podemos asegurar que Bernabé Lobato era o bien indio, pues su madre lo era, o bien mestizo, pero no español. Como muy tarde nacería hacia 163638, siendo más o menos coetáneo de Miguel de Santiago y de Simón de Valenzuela.

Costales Samaniego nombra en una publicación a un Bernardo Lovato, pintor mestizo citado en 1663 en el testamento de Ana de Cabrera, a quien el pintor había dejado una escultura como prenda por una deuda contraída con la testadora ${ }^{50}$. Por ello, Costales Samaniego supuso que también era escultor, aunque esta suposición resulta un tanto aventurada, pues Lovato pudo entregarle una pieza perteneciente a sus posesiones pero no realizada por él. De todas maneras, si este Bernardo Lovato no es Bernabé, a quien se equivocaran al citarlo en el testamento, quizás fuese su padre, de manera que Bernabé fuese hijo, nieto y medio sobrino de pintores. En caso de que sea él, confirma nuestra suposición de pintor mestizo, pues así se lo califica en el testamento de Ana de Cabrera ${ }^{51 .}$

En enero de 1662, Juana Flores, india soltera de la collación de Santa Bárbara, traspasó a Bernabé Lobato un pedazo de tierra yermo, que la otorgante había comprado a Francisca Mendiola, abuela del pintor, en el Alto de Santa Bárbara, por 25 pesos $^{52}$. No obstante, a pesar de ser la otorgante la propietaria legal, el pintor había pedido esas tierras, cediendo Juana Flores y traspasándoselas. El mismo 3 de enero de 1662 Bernabé Lobato, al que se alude como oficial pintor, vende a Miguel de Santiago, maestro pintor, un pedazo de tierra yerma "de hasta catorce varas de largo y ocho de ancho", en el Alto de Santa Bárbara, por una precio de 25 pesos de a ocho reales ${ }^{53}$. Esta parcela lindaba con la casa de don Blas, maestro de danza, con la de Bernabé Pabón, con tierras de Francisca india y con la calle real, siendo la misma que Lobato había comprado a Juana Flores. El dinero que aportó Miguel de Santiago para realizar la adquisición de este solar no era suyo, sino de Ana Rozero; ésta se lo había entregado para que el maestro pintor la comprase, tal como reconoce el propio Santiago en una declaración a favor de ella fechada en marzo de $1669^{54}$.

50 Costales Samaniego, 2007, p. 222.

51 Citado en Ibídem.

52 Traspaso de un pedazo de tierra, de Juana Flores, india soltera, a Bernabé Lobato. Quito, 3-I1662. ANH, sección Protocolos Notariales, $1^{\text {a }}$ notaría, vol. 206, ff. 607r-608r.

53 Venta de un pedazo de tierra yerma, de Bernabé Lobato, oficial pintor, a Miguel de Santiago, maestro pintor. Quito, 3-I-1662. ANH, sección Protocolos Notariales, $1^{\text {a }}$ notaría, vol. 206, ff. 608r-610v.

54 Declaración de Miguel de Santiago a favor de Ana Rozero. Quito, 2-III-1669. ANH, sección Protocolos Notariales, $1^{a}$ notaría, vol. 226, ff. 85r-v. Para mayor información sobre la adquisición de la parcela y de otras posesiones del maestro, véase Justo EsteBARANZ, 2008b, pp. 185-189. 
No sabemos cuándo falleció Bernabé Lobato, pues tras estos documentos se le pierde la pista. Al menos vivió hasta 1662 o 1663, si es que Bernardo Lovato realmente es Bernabé Lobato. Lo que sí queda claro es que este pintor colaboró con Miguel de Santiago durante los primeros años de su actividad pictórica, junto a Simón de Valenzuela, Bernabé Carreño y fray Alonso Vera de la Cruz.

\section{FRAY ALONSO VERA DE LA CRUZ}

Alonso Vera de la Cruz fue un fraile agustino residente en el convento quiteño en los años en que se llevaba a cabo la decoración pictórica del claustro con los lienzos de la vida de San Agustín. Como en el caso de Bernabé Lobato, su nombre presenta también algunos errores o equivocaciones, pues aparece citado como Alonso Vera de la $\mathrm{Paz}^{55}$, pese a que él firmaba en los documentos como Alonso Vera de la Cruz ${ }^{56}$. El religioso agustino había sido vinculado al obrador de Miguel de Santiago en la época de la realización de las pinturas de San Agustín, por hallarse firmado un cuadro suyo que representaba al arcángel Uriel. El agustino, nombrado como "fray Alonso de la Cruz Religioso del orden de Sant Augustin", figuraba en un testamento de 1659 como destinatario de 9 pesos por otras tantas misas que dijo al testador, Joan Arias Gonzalo ${ }^{57}$. Otro documento notarial corrobora su actividad como pintor: en el testamento de Gerónima de Peralta, ésta dice que había hecho un concierto "con fray Alonsso que no se me acuerda su sobrenombre que es pintor y Religioso del combento de Sant Augustin", por el cual el agustino habría de decir cincuenta misas por su intención, y en caso de haber cumplido con dicho compromiso, la testadora manda que los albaceas le paguen por ellas 50 pesos ${ }^{58}$. Está claro que este fray Alonso pintor y religioso de San Agustín es fray Alonso Vera de la Cruz. Puesto que el testamento data de 22 de mayo de 1674 , sabemos que al menos hasta esa fecha fray Alonso seguía vivo y que quizás continuase su labor como pintor, pues como tal lo nombra Gerónima de Peralta. Por lo tanto, su actividad artística se podría encuadrar en el tercer cuarto del siglo XVII, al menos entre 1654 y 1674 . Pero además de su actividad como pintor, su propia condición de agustino le llevó a intervenir en otras labores, firmando en algunos documentos notariales relacionados con negocios y convenios establecidos entre su cenobio y particulares quiteños, como se ha citado anteriormente.

55 NAVARRO, 1950, p. 105.

56 Así lo atestigua su firma en el Primer y segundo tratado del Convento de San Agustín sobre la venta de unas tierras a Cristóbal Méndez, presbítero, y Juan Méndez, su hermano. Quito, 7-III-1656 y 10-III-1656. ANH, sección Protocolos Notariales, 5a notaría, vol. 45, ff. 151 y 155 . En cambio, su firma no aparece en el tercer tratado con los dos hermanos, quizás porque permaneciera pintando los lienzos en esas fechas. También firma fray Alonso en un Poder que da el convento de San Agustín a Joan de Esteissa y en otro Poder que da el convento de San Agustín a Juan de Santiago y Joan Adonde Peralta, padres de la Compañía de Jesús. Ambos documentos, correspondientes al año 1665, en ANH, sección Protocolos Notariales, $5^{\text {a }}$ notaría, vol. 54, ff. 232v-234r, y 235r-236r.

57 Testamento de Joan Arias Gonzalo. Quito, 1659. ANH, sección Protocolos Notariales, $5^{a}$ notaría, vol. 48 , f. $138 \mathrm{v}$.

58 Testamento de Gerónima de Peralta. Quito, 22-V-1674. ANH, sección Protocolos Notariales, $1^{\text {a }}$ notaría, vol. 234 , f. $338 \mathrm{v}$. 


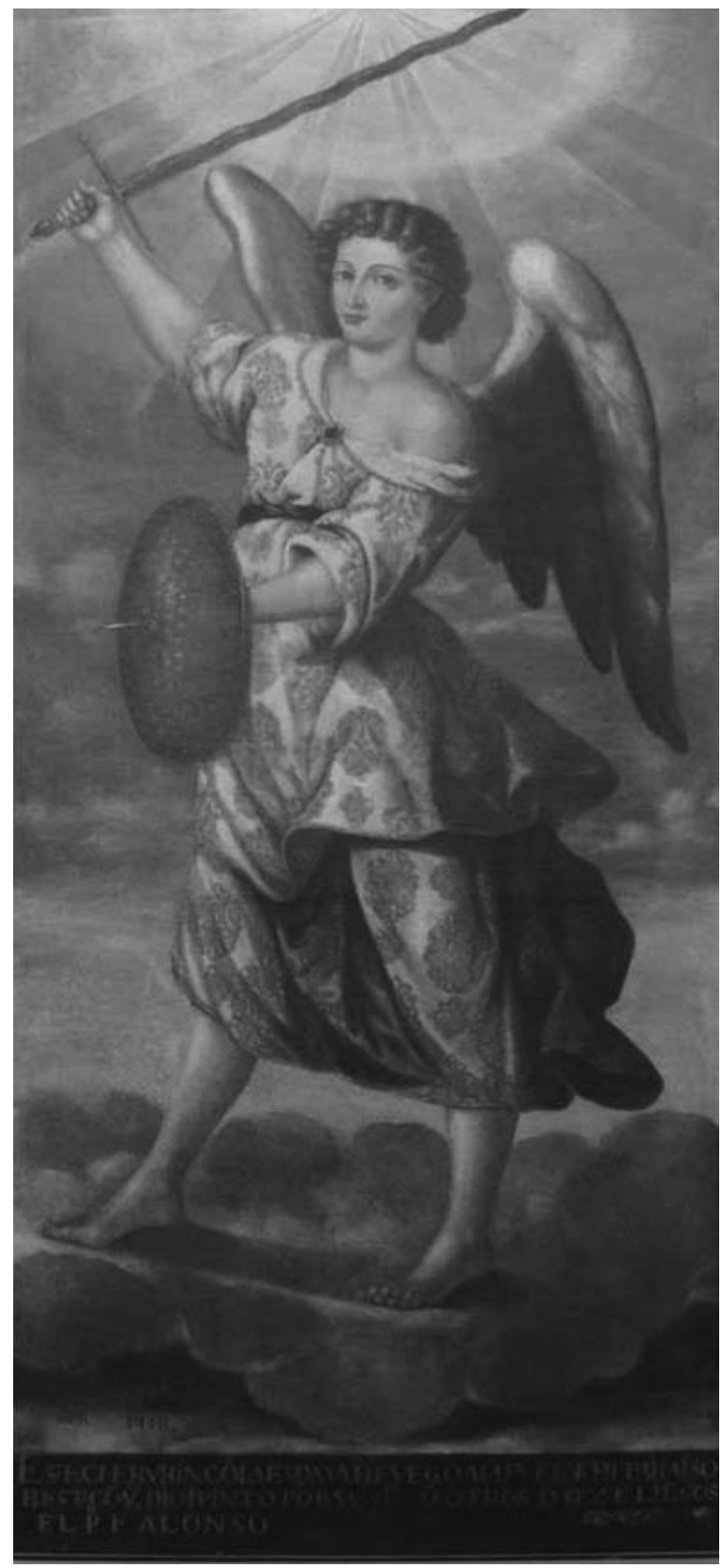

Fig.1:Fray Alonso Vera de la Cruz: Uriel (Convento de San Agustín de Quito, Museo, ca. 1656)*

* N. de la R.: Las imágenes adjuntas pueden verse con mayor resolución en la versión digital [www.ucm.es/BUCM/revistasBUC/portal]. 
Según Terán, la producción de fray Alonso Vera de la Cruz se caracteriza por la "esbeltez en los personajes, colorido sobrio, poco recargado y casi aéreo, finura y delicadeza del pincel en la decoración" 59 . El análisis de su obra firmada, sin embargo, revela otras características bien distintas. Esta pintura había sido tradicionalmente identificada como un Querubín, pues así lo atestigua la inscripción en la parte inferior del lienzo: ESTE CHERUBIN CO(N) LA ESPADA DE FUEGO A LA PUERTA DEL PARAISO DE ESTE CO(N)V(EN)TO DIO I PINTO POR SU Q(UEN)TA (C)O(N) OTROS DOZE LIE(N)ÇOS EL P(ADR)E F ALONSO. Pero la inscripción no se refiere a querubín en ese sentido, sino a ángel, pues a quien representa es a Uriel guardando la puerta del Paraíso, armado con la espada de fuego.

El arcángel se ha representado en primer plano, sobre un fondo nuboso en tonos grises que se destaca sobre un cielo azul parcialmente cubierto. Las nubes sobre las que pisa Uriel son más densas, habiendo cargado el pintor más las tintas. Debajo de ellas parece entreverse el suelo campestre. La zona superior del lienzo, la más luminosa, está ocupada por un sol resplandeciente en tonos ocres claros y amarillos, que se abre en semicírculos concéntricos hacia Uriel. Ésta es la fuente de luz que destaca a la figura del arcángel, ataviado con una túnica blanca decorada con profusión de detalles que imitan bordados en oro, y sujeta con un cinto a la cadera del arcángel. Si el hombro derecho está cubierto, no sucede lo mismo con el izquierdo, habiéndose colocado un broche que sujeta la túnica. La composición es eminentemente vertical. El movimiento que fray Alonso ha pretendido dar a Uriel resulta un tanto forzado, pues la elevación del brazo derecho con la espada de fuego, la sujeción del escudo con el izquierdo, el adelantamiento de la pierna derecha y el giro de su cabeza hacia el espectador se antojan rígidos y faltos de la naturalidad que proporcionaba Miguel de Santiago a sus figuras. Por otra parte, el dibujo es más marcado, observándose un detallismo excesivo en la recreación de los rizos del cabello, y unos rasgos faciales destacados sobre un rostro sin apenas matices de sombras que proporcionen volumen a la figura, excepción hecha de unos coloretes poco realistas. Asimismo, son evidentes ciertos errores anatómicos en el modelado del cuerpo, sobre todo en los pies. Además, la aplicación del colorido tanto, en el rostro como en el hombro izquierdo resulta bastante plana. Por lo tanto, esta obra revela a un pintor de mediocres capacidades, más afín a la pintura que se practicaba en la capital de la Real Audiencia hasta el momento de la irrupción de Miguel de Santiago que a la de este maestro.

El lienzo de Uriel del museo del convento de San Agustín no sería el único que el religioso pintara para su cenobio, pues la inscripción de la parte inferior dice que el padre fray Alonso dio y pintó este cuadro con otros doce más. Si fue él quien realizó tal inscripción, es muy posible que el agustino fuera el autor de las que aparecen en los cuadros de la serie de la vida de San Agustín, pues coincide formalmente con ellas.

59 TERÁN, 1950, pp. 130-131. 


\section{BERNABÉ CARREÑO}

De Carreño no se había encontrado hasta el presente ninguna documentación. Resulta paradójico que en Quito los pocos cuadros firmados en el siglo XVII pertenecen, salvo excepciones, a pintores cuya presencia documental es inexistente hasta la actualidad, mientras que de otros ampliamente representados en los archivos capitalinos no se ha encontrado aún ningún cuadro firmado. Al menos sabíamos que Carreño colaboró con Miguel de Santiago en las pinturas de San Agustín, por lo que habría sido compañero de obrador de Lobato y Valenzuela, perteneciendo a esa primera generación de discípulos ${ }^{60}$.

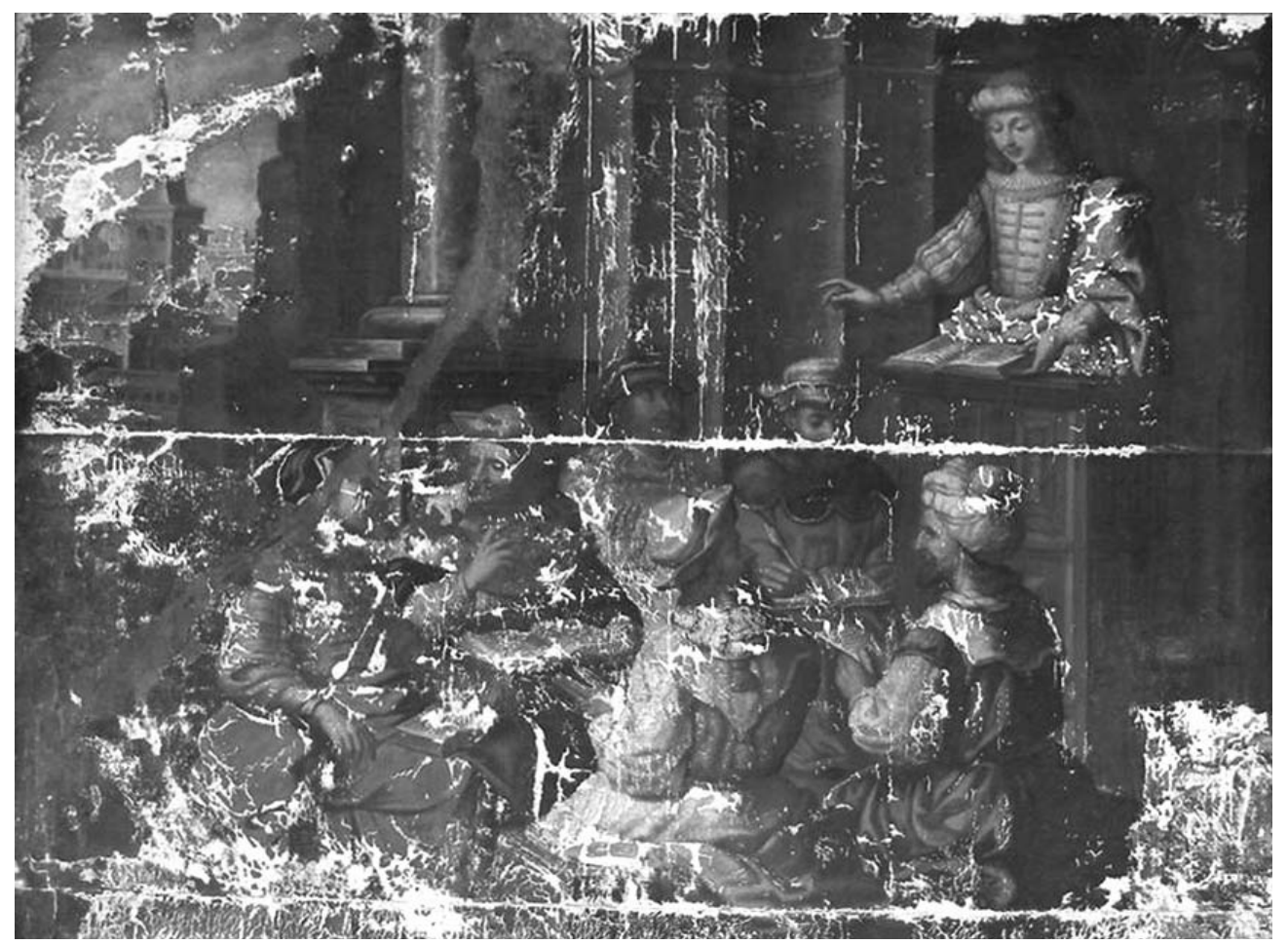

Fig. 2: Bernabé Carreño: San Agustín enseña retórica en Milán

(Convento de San Agustín de Quito, galería sur del claustro, 1656)

Un único documento encontrado en el Archivo Nacional de Historia de Quito permite documentar a Carreño en Quito. Es un contrato de venta entre Bernabé Carreño, maestro pintor residente en la capital, y don Tomás Pillaxo, maestro cantor del convento de San Francisco de Quito, firmado el 10 de octubre de 166761. En él,

60 También Vargas y Barrera consideraron a Carreño como discípulo de Miguel de Santiago. Véase VARGAS, 1960, p. 189 y BARRERA, 1979, p. 230.

61 ANH, sección Protocolos Notariales, $4^{a}$ notaría, vol. 26, f. 247 r-v. Agradezco a la Dra. Susan V. Webster el haberme facilitado la localización del documento. 
Carreño vende al músico unas tierras llamadas Patucutocque en el pueblo de San Antonio de Pomasque, de cinco cuadras de largo por tres y media de ancho, las cuales había comprado de Angelina Yocassa india. La venta se fijó en un precio de 60 pesos de a 8 reales. Este documento es importante porque sitúa al pintor en Quito un decenio después de terminada la serie de la Vida de San Agustín, y porque muestra que Carreño llegó a conseguir el grado de maestro pintor, cosa que no sabemos con certeza de los otros discípulos de la primera generación de Miguel de Santiago.

Aunque este pintor firmase solamente un cuadro del convento agustino, debería haber pintado otros más de la serie. A Carreño se debe con certeza la pintura de San Agustín enseña retórica en Milán, pues su firma consta en este lienzo de la galería sur del claustro de San Agustín de Quito ${ }^{62}$. Aunque dicha pintura revela a un autor de aceptables capacidades, no está a la altura de Miguel de Santiago, mostrándose menos hábil en el manejo del colorido, en el tratamiento de los paños y en la disposición en perspectiva de ciertos elementos como el estrado en el que San Agustín dicta la lección. Carreño se revela en este detalle como un pintor incapaz de dar una creíble sensación de profundidad, al introducir una venera que remata el estrado y que se aprecia tras la figura del santo. En nuestra monografia sobre las pinturas de la serie de San Agustín señalamos que Carreño pudo realizar, asimismo, las escenas de San Agustín se aparece al duque de Mantua y del Nacimiento del santo (ésta en colaboración con Miguel de Santiago), por semejanzas en el tratamiento del colorido y el dibujo ${ }^{63}$.

\section{BALANCE DEL MAGISTERIO}

Fueron los oficiales de los que tratamos en este artículo quienes intervinieron en la decoración pictórica del claustro de San Agustín, en las pinturas de la portería de San Francisco y en la Doctrina cristiana conservada en el Museo Fray Pedro Gocial de dicho convento. El análisis de las pinturas del obrador de Santiago en este período permite apreciar sus características. En los primeros años (o sea, en las pinturas de la Vida de San Agustín, que comenzarían hacia 1654 y terminarían en 1656), y dejando de lado a fray Alonso Vera de la Cruz que parece tener un estilo más diferenciado, el resto sigue al maestro en cuanto al uso de sombras y colorido, aunque con desigual fortuna. Por regla general, las composiciones de las pinturas les vienen dadas por los grabados de Schelte de Bolswert sobre la vida de San Agustín -por ejemplo, en San Agustín difunto se aparece al Duque de Mantua, o en La traslación de la reliquia del santo, donde colaboró el maestro en algunos rostros ${ }^{64}$. En el caso de algunos cuadros que no tuvieron estos grabados flamencos como modelo, la composición procede de otras estampas que probablemente escogería Miguel de Santiago y facilitaría a sus discípulos, entregándoles un boceto sobre el que trabajarían siguiendo sus indicaciones - es el caso del lienzo San Agustín Luz de los Doctores ${ }^{65}$. La distribución de luces y sombras les

62 En un pliegue de uno de los discípulos aparece la inscripción "Faciebat Carreño, 1656 años". Véase Justo Estebaranz, 2008a, p. 227.

63 Ibidem, pp. 82-84.

64 Véase Justo Estebaranz, 2008a, pp. 170-174 y 258-261.

65 Ibidem, pp. 194-197. 
vino dada por los grabados de Bolswert, de los que, al igual que el maestro, aprendieron varios conceptos. La menor valentía de pincelada es rasgo del obrador, así como un menor dominio de las medias tintas y las veladuras.

Pero no todos los colaboradores de Santiago tuvieron las mismas dotes artísticas, como se puede observar en las escenas de esta serie sobre la vida de San Agustín pintadas por el obrador. Uno de ellos, autor de la Visión de Santa Gertrudis, es capaz de

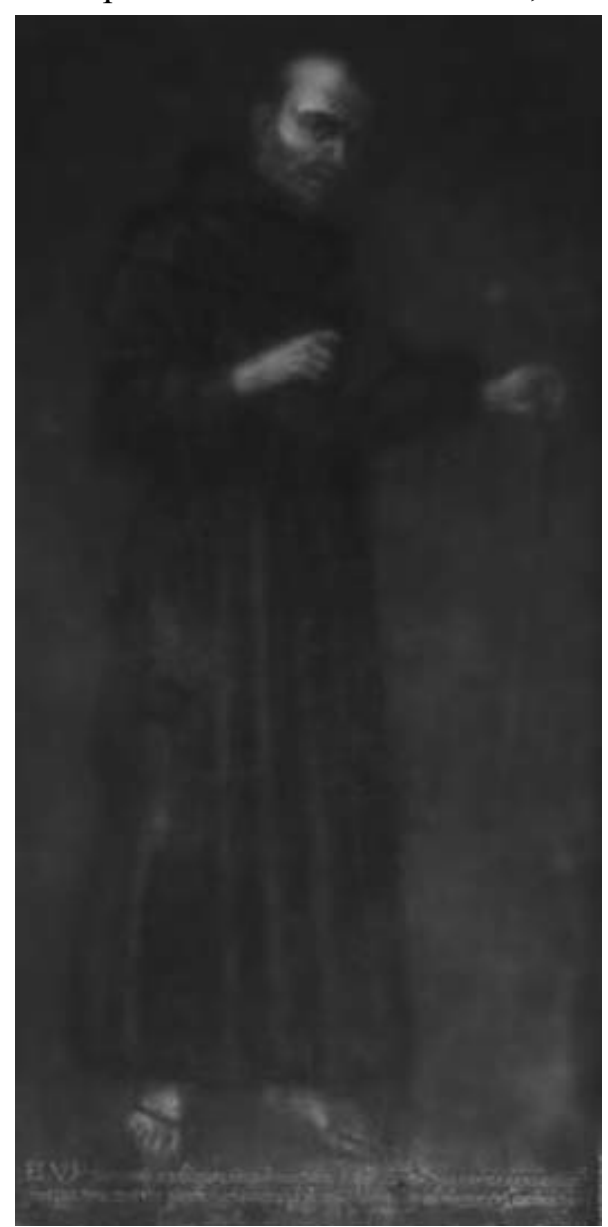

Fig. 3: Obrador de Miguel de Santiago: Fray Antonio Rodrígues.

(Portería del Convento de San

Francisco, Quito, ca. 1670) dotar a los angelitos que esparcen flores de una naturalidad y amabilidad de gestos que está por encima del resto de sus compañeros. Esta pintura contrasta con otras más rígidas como La caridad de San Agustín, donde un colorido seco se suma a una composición erróneamente interpretada ${ }^{66}$. La representación de los rostros más expresivos y de detalles de bodegón quedó a cargo casi por completo de Miguel de Santiago. No obstante, hay muestras en esta serie de intentos de algún colaborador, quizá Lobato o Valenzuela, de probar bodegones ellos mismos, con resultado fallido. Estas muestras se pueden encontrar en el cuadro del Nacimiento del santo, donde dos soberbias muestras de bodegón en forma de un cesto de frutas y una jofaina de cerámica, sin duda de la mano del maestro, contrastan con un cesto de mimbre con sábanas falto de sutileza, con un dibujo menos suelto ${ }^{67}$. Este detalle, realizado por un colaborador, ejemplifica a la perfección la diferencia de calidad y de entidad artística entre maestro y discípulos.

Las pinturas de San Agustín aún poseen claros matices claroscuristas que más adelante se abandonarán totalmente, como puede comprobarse en la portería del convento de San Francisco de Quito, que representan a frailes de la orden. A diferencia de los dos pintados por Santiago (Fray Domingo de Brieva y Fray Pedro Pecador), que incluyen otros personajes,

66 Ibídem, pp. 132-133. Así, la escena del interior de una habitación, donde figuran San Agustín y varios mendigos, se ha yuxtapuesto a otra de un claustro con dos clérigos arrojando cálices a un horno de fundición. Pero entre ellas no hay una transición creíble ni ajustada a reglas de perspectiva.

67 Ibidem, pp. 224-225. 
los cuatro frailes realizados por el obrador aparecen solos sobre un fondo neutro de color oscuro. Visten el hábito franciscano y ocupan prácticamente toda la superficie del lienzo, lo que les otorga una mayor monumentalidad potenciada por su situación en alto. Esta forma de componer sigue las pautas que el maestro había utilizado en las pinturas de Fray Domingo y Fray Pedro, optando por el formato vertical como el más conveniente, tanto para el lugar en el que se habían pintado, cuanto para el tema representado. El efecto claroscurista de estas pinturas está acentuado por la luz que entra en la portería a través de dos vanos cubiertos con rejas (las puertas), que propician que al primer golpe de vista se destaquen los rostros de los frailes sobre la

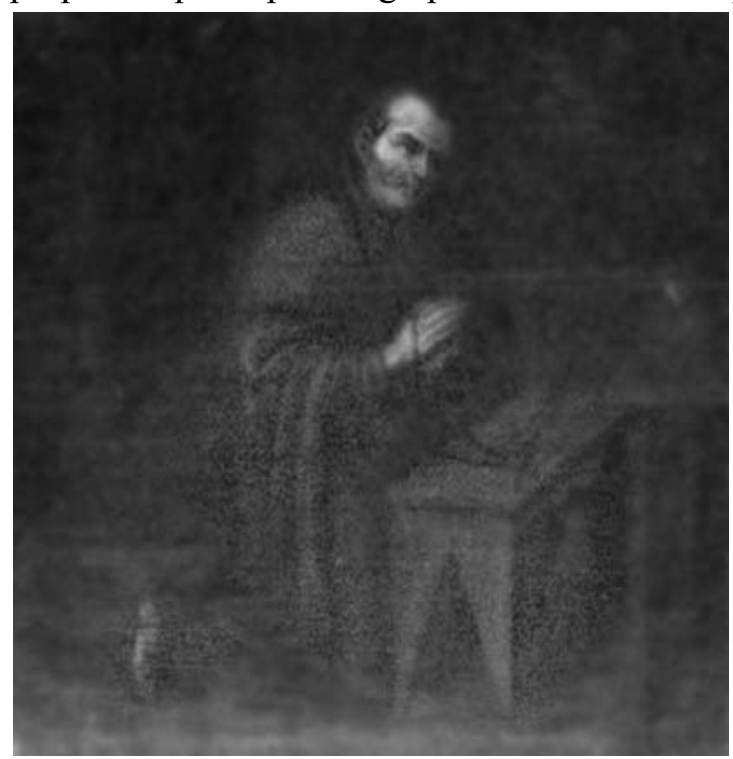

Fig. 4: Obrador de Miguel de Santiago:

Fray Francisco Guerrero.

(Portería del Convento de San Francisco, Quito, ca. 1670) oscuridad de su hábito y del fondo. Además, la iluminación incide más sobre las pinturas de la Flagelación (sobre todo en el cuerpo de Cristo), Fray Pedro Pecador, Santo Domingo y San Francisco y las hojas de la hornacina (con los ángeles, que flanquean al cuadro de la Virgen de los Dolores). Esta distribución de la iluminación pudo estar pensada por Santiago, de modo que se potenciasen los contrastes lumínicos. De hecho, la figura de Fray Pedro Pecador, de su propia mano, se destaca sobre un fondo de paisaje grisáceo, en tonos más claros que el resto de cuadros. Aunque la Virgen de los Dolores es obra del siglo XIX, probablemente la pintura original a la que sustituye siguiera unas pautas de iluminación semejantes.

Por lo que respecta a estas obras, que se pueden fechar hacia 1670 o quizás un poco antes, se aprecia la influencia del maestro en los discípulos a la hora de representar unos rostros expresivos y bien modelados. Estos frailes se interpretan como personajes de facciones enjutas y manos delgadas, indicativas de su vida recia y llena de privaciones.

El Crucificado de la portería del cenobio franciscano de Quito, situado frente a la pintura de la Virgen de los Dolores, había sido considerado por algunos autores como obra del propio Miguel de Santiago ${ }^{68}$. El Crucificado es una obra de un gran tenebrismo (que además queda a contraluz, lo que acentúa la sensación tenebrista), realizada hacia 1670, en el momento en el que se lleva a cabo la decoración pictórica con los retratos de algunos franciscanos ilustres del convento. Creemos que es obra de Bernabé Lobato o Simón de Valenzuela, pues aunque tiene influencias del

68 Gento SANZ, 1940, p. 44. 
maestro, revela una menor soltura de pincelada. El modelado del torso se corresponde con el del Cristo que aparece en la Flagelación de la misma portería. Quizás se deba a la intervención del mismo pintor, pero no a la del maestro.

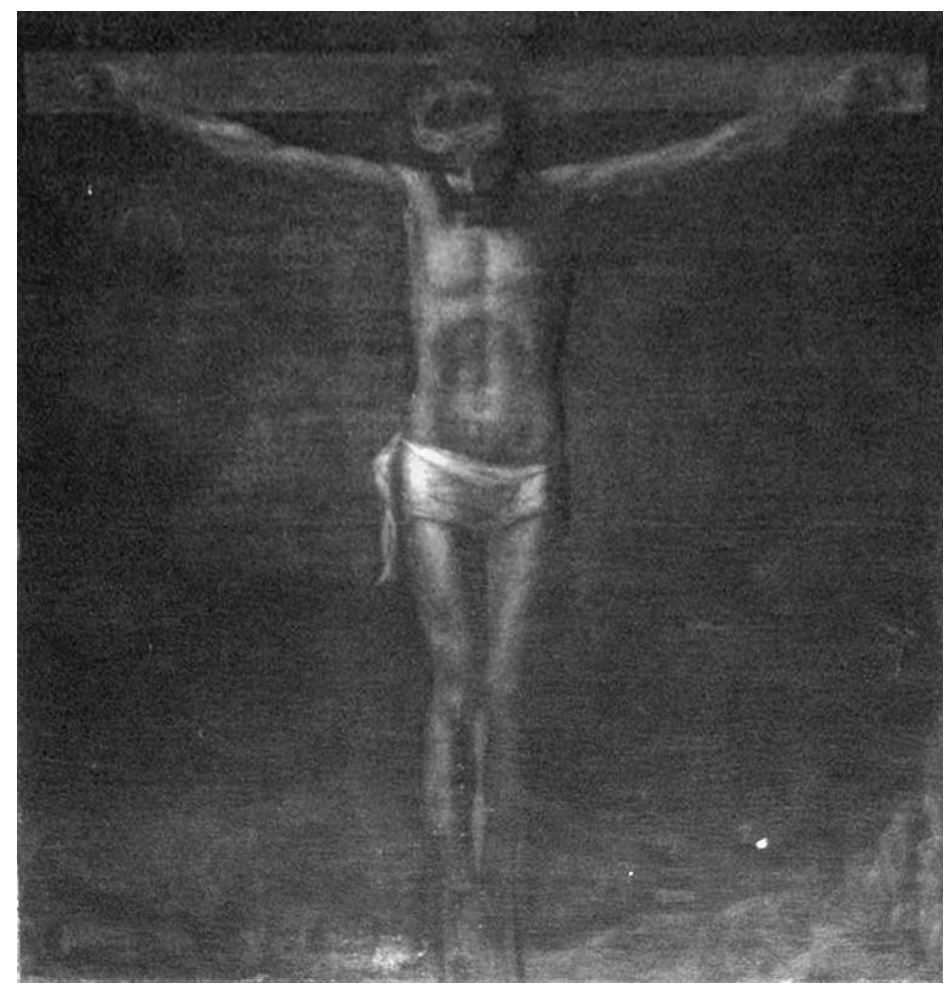

Fig. 5: Obrador de Miguel de Santiago: Crucificado. (Portería del Convento de San Francisco, Quito, ca. 1670)

Las pinturas de la Doctrina cristiana y de las otras series doctrinales, realizadas en la primera mitad de los 70, muestran el paso a una mayor luminosidad y a una pincelada más suelta, tanto en la producción de Miguel de Santiago como en la de los integrantes de su obrador. Estos colaboradores intervienen sobre todo en la serie del Alabado de Bogotá, de una menor calidad global que la conservada en el cenobio seráfico quiteño. En la Doctrina cristiana, el obrador se encarga de la ejecución de ciertas figuras que vuelven a mostrar las mismas diferencias de calidad respecto a Miguel de Santiago. No obstante, la pincelada se vuelve más suelta y la paleta se aclara, utilizando también los discípulos veladuras según el gusto del maestro, como se puede comprobar en las figuras de la Justicia y de la Petición del Padrenuestro del lienzo No matarás, perteneciente a la Doctrina cristiana. Ello demuestra que el obrador de Miguel de Santiago fue evolucionando conforme lo hacía su maestro, tratando de amoldarse a los logros pictóricos de aquél, aunque sin alcanzarlos del todo. 


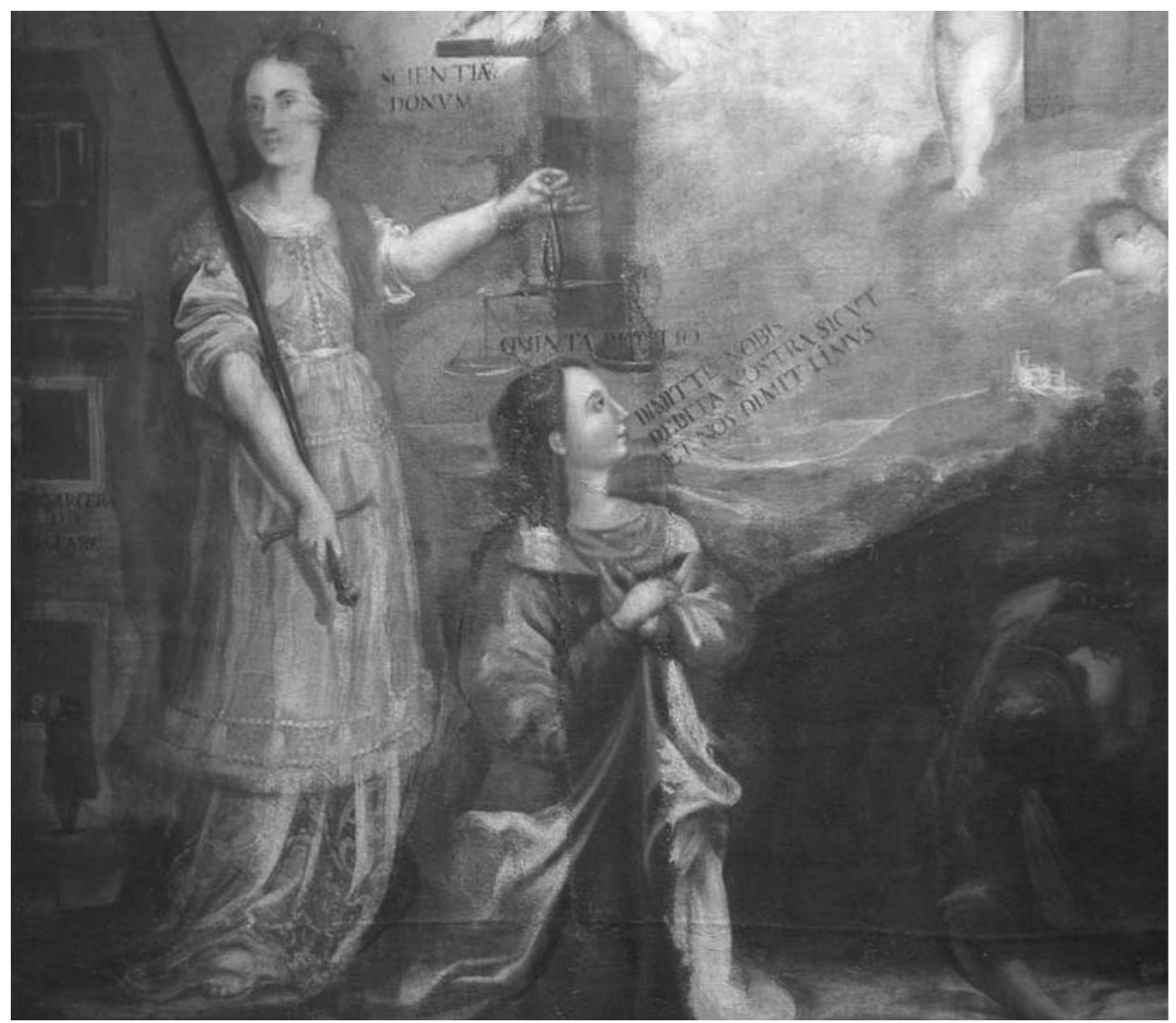

Fig. 6: Detalle de No matarás (perteneciente a la Doctrina cristiana, ca. 1670), en el que se observa la intervención del taller en las figuras de la Justicia y de la Petición del Padrenuestro (Museo del Convento de San Francisco, Quito)

\section{CONCLUSIONES}

Para finalizar, resaltamos algunas conclusiones referentes al obrador de Miguel de Santiago en su etapa más temprana. El maestro dirigió, desde su primera producción, un gran obrador en el que trabajaron algunos de los pintores quiteños más capacitados de su momento en el ámbito de la capital de la Real Audiencia. En el taller de Santiago desarrollaron su labor artistas de diferente raza (indios, mestizos y mulatos, y hasta un español en época posterior), algunos de ellos emparentados con el propio maestro, circunstancia bastante común en los talleres artísticos de la Edad Moderna. La producción del obrador de Santiago sería singularmente superior a las de otros artistas quiteños coetáneos. Por ello, y desde sus comienzos, el obrador de 
Miguel de Santiago gozó de gran prestigio entre la clientela más poderosa del Quito de la época, sobre todo entre las órdenes religiosas que acudirían a él para la decoración pictórica de sus cenobios e iglesias. A pesar de la superior calidad de las pinturas de los colaboradores de Santiago respecto a otros pintores de Quito, la obra del maestro es de mayor categoría artística que la de sus discípulos. Esta diferencia de nivel artístico se mantendrá en la segunda generación de colaboradores de Miguel de Santiago, entre los que se contarán su hija Isabel, Antonio Egas y Nicolás Javier de Goríbar.

\section{REFERENCIAS BIBLIOGRÁFICAS}

Alarcón CostTa, César Augusto

2000 Diccionario Biográfico Ecuatoriano. Quito. Fundación Ecuatoriana de Desarrollo - FED - Editorial Raíces.

Alcalá, Luisa Elena

1998 "Fue necesario hacernos más que pintores... Pervivencias y transformaciones de la profesión pictórica en Hispanoamérica". En CHECA CREMADES, Fernando (coord.). Las sociedades ibéricas y el mar a finales del siglo XVI. Catálogo de Exposición. Pabellón de España. Madrid. Ediciones El Viso, pp. 85-106.

BARGELLINI, Clara

2006 "Consideraciones acerca de las firmas de los pintores novohispanos". En Dallal, Alberto (ed.). El proceso creativo. México. UNAM, pp. 203-222.

BARRERA, Isaac J.

1979 Historia de la Literatura Ecuatoriana. Tomo I. Quito. Libresa.

CONTRERAS, Juan de (Marqués de Lozoya)

1945 Historia del Arte Hispánico. Tomo IV. Barcelona. Salvat.

CORTÉs Alonso, Vicenta

1967 "Los esclavos domésticos en América". Anuario de Estudios Americanos. Sevilla. vol. XXIV, pp. 955-983.

Costales Samaniego, Alfredo

2007 "El arte en la Real Audiencia de Quito. Artistas y artesanos desconocidos de la Escuela quiteña". En Fernández-SAlvador, Carmen Costales Samaniego, Alfredo. Arte colonial quiteño. Renovado enfoque y nuevos actores. Quito. FONSAL, pp. 125-315.

Destruge, Camilo

1903 Álbum biográfico ecuatoriano. Tomo I. Guayaquil. Tipografía El Vigilante.

DICCIONARIO

1972 Diccionario Enciclopédico Abreviado. $7^{\mathrm{a}}$ edición. Tomo III. Madrid. Espasa-Calpe S. A.

Gento Sanz, Benjamín

1940 Guía del turista en la iglesia y convento de San Francisco de Quito. Quito. Imprenta Americana. 
GuIDO, Ángel

1944 Redescubrimiento de América en el Arte. $3^{\mathrm{a}}$ edición. Buenos Aires. Librería y Editorial El Ateneo.

GuTIÉRREZ, Ramón

1995 "Los gremios y academias en la producción del arte colonial". En Gutiérrez, Ramón (coord.). Pintura, escultura y artes útiles en Iberoamérica, 1500-1825. Madrid. Cátedra, pp. 25-50.

Justo Estebaranz, Ángel

2008a Miguel de Santiago en San Agustín de Quito. La serie de pinturas sobre la vida del santo. $2^{\mathrm{a}}$ edición corregida y aumentada. Quito. FONSAL (con la colaboración de la Embajada de España en Ecuador).

2008b Miguel de Santiago y la pintura quiteña de su época (1630-1720). Tesis Doctoral leída en la Universidad de Sevilla el 16/07/2008.

2009 "Pintores sevillanos en Quito en el siglo XVII: Antonio Egas y Juan Esteban Espinosa de los Monteros". En Andalucía-América: cultura artística. Granada. Atrio, pp. 75-97.

KENNEDy, Alexandra

2002 "Algunas consideraciones sobre el arte barroco en Quito y la interrupción' ilustrada (siglos XVII y XVIII)”. En KenNEDY, Alejandra (ed.). Arte de la Real Audiencia de Quito, siglos XVII-XIX. Patronos, corpoKINGMAN, Eduardo raciones y comunidades. Hondarribia. Editorial Nerea, pp. 43-65.

1951 Guía del Museo de Arte Colonial. Quito. Casa de la Cultura Ecuatoriana.

NAVARro, José Gabriel

1950 Contribuciones a la Historia del Arte en el Ecuador. Volumen III. Quito. Litografía e Imprenta Romero.

1985 Artes Plásticas Ecuatorianas. Quito. s.d.

1991 La pintura del Ecuador del XVI al XIX. Quito. Dinediciones.

Rodríguez CASTELo, Hernán

1993 Panorama del arte. Biblioteca Ecuatoriana de la Familia n ${ }^{\circ}$ 9. Quito. Ministerio de Educación y Cultura del Ecuador. Edit. Corporación Editora Nacional - Casa de la Cultura Ecuatoriana - Editorial El Conejo. http://www.edufuturo.com/educacion.php?c=1750.

SANTA CRUZ y EsPEJO, Francisco Javier Eugenio de

1923 "Defensa de los curas de Riobamba" [1786]. Escritos de Espejo. Tomo III. Quito. Editorial Artes Gráficas, pp. 3-233.

TARDIEU, Jean-Pierre

2006 El negro en la Real Audiencia de Quito (Ecuador), ss. XVI-XVIII. Quito. Ediciones Abya-Yala.

TERÁn, Enrique

1950 Guía explicativa de la Pinacoteca de Cuadros Artísticos y Coloniales del Convento de San Agustín, precedida de las Biografias del P. Basilio de Ribera y Miguel de Santiago. Quito. Imprenta Bona Spes-San Agustín. 
ToBar Donoso, Julio

1953 La Iglesia, modeladora de la nacionalidad. Quito. La Prensa Católica. Toussaint, Manuel

1965 Pintura colonial en México. México. Instituto de Investigaciones Estéticas-UNAM.

VARGAS, José María

1944 Arte Quiteño Colonial. Quito. s.d.

1960 El arte ecuatoriano. Puebla. Editorial J. M. Cajica.

Velasco, Juan de

1981 Historia del Reino de Quito en la América Meridional [1789]. Tomo II, parte II. Caracas. Editorial Arte. 